\section{Handful of papers dominates citation}

An 'impact disparity' is emerging in science - only a few papers earn the largest share of citations. This is comparable to the income disparity in the United States, known as the $1 \%$ phenomenon, where $1 \%$ of the population earns a disproportionate $17.4 \%$ of total income (see go.nature.com/ yajthu).

The number of citations acquired by a paper is a proxy of its impact. We found that of all papers published in five leading journals in 1990, the most highly cited $1 \%$ in each collected around $17 \%$ of citations in 2010 (see 'The 1\% effect'; data from Thomson Reuters Science Citation Index).

Changes over time in the citation share of the top $1 \%$ are evidence of endogenous shifts in underlying processes. These trends are particularly pronounced for citations of older papers. For example, the top $1 \%$ of 1990 papers collected only about $5 \%$ of citations in 1991 .

This shift of attention over time towards the top $1 \%$ may reflect the fact that, although the number of research papers has exploded, the time scientists devote to reading them has not. Researchers increasingly rely on crowd sourcing to discover relevant work, a process that favours the leading papers at the expense of the remaining 99\%.

Albert-László Barabási, Chaoming Song, Dashun Wang Northeastern University, Boston, Massachusetts, USA. barabasi@gmail.com

\section{Call to register new species in ZooBank}

We wish to clarify a few points in your discussion of the decision by the International Commission on Zoological Nomenclature (ICZN) to allow naming of new species in electronic-only publications (Nature 489, 178; 2012).

\section{THE 1\% EFFECT}

The top $1 \%$ of the most highly cited papers published in 1990 have accrued a disproportionate share of citations over the past 20 years.

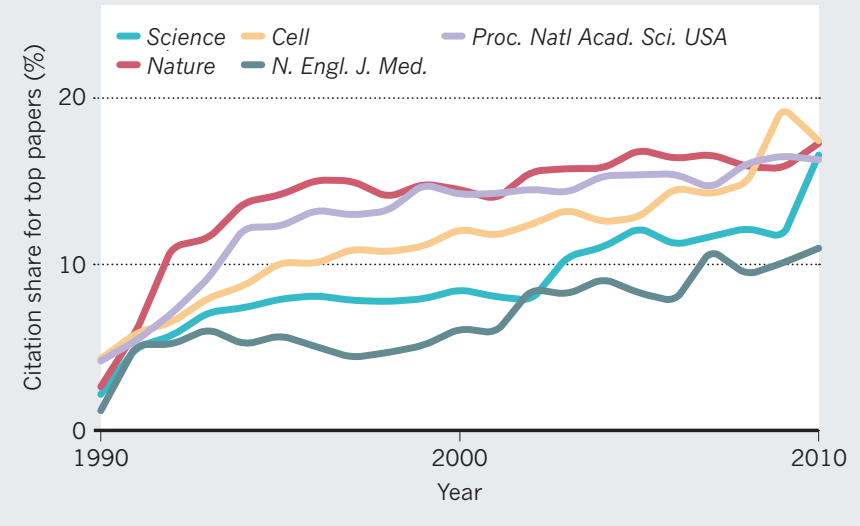

The amendment is already in force, retroactive to 1 January 2012 (see, for example, Bull. Zool. Nomenclature 69, 161-169; 2012; available at go.nature.com/atytlr). It remains to be seen which electronic publication will first satisfy the requirements of the amendment. The ICZN official registry, ZooBank, did not support all the requirements until the beginning of September, when the commissioners' votes became official.

New animal species will not need to be registered in ZooBank. It is the electronic works themselves that must be registered to count as published for nomenclatural purposes. In the amendment, registration of new names is a recommendation, not a requirement. We encourage zoologists to comply with this recommendation, which will aid in automated indexing, linking and data extraction.

The amendment allows the ICZN to issue declarations clarifying whether new methods of production, distribution, formatting or archiving can be used to publish works that comply with the requirements of the International Code of Zoological Nomenclature. This, coupled with the error-checking capabilities in ZooBank, will enable the code to evolve rapidly new requirements.

Gary Rosenberg Drexel

University, Philadelphia,

Pennsylvania, USA.

rosenberg@ansp.org

Frank-T. Krell Denver Museum

of Nature \& Science, Denver,

Colorado, USA.

Richard Pyle Bernice P. Bishop

Museum, Honolulu, Hawaii,

USA.

\section{Problems enforcing Ecuador ecology law}

Ecuador has more species per unit area than any other country, a unique ecology that is now uniquely protected under its constitution. But upholding these highly commendable conservation policies is a challenge.

For example, a landmark legal precedent was set in a lawsuit brought in early 2011 against the local government for damages to the Vilcabamba River caused by a road-construction project. The defendant was ordered to pay for recuperation of the river. One year on, there has still been no substantial remediation (see go.nature.com/6m4aea).

In light of this situation, we are concerned that the imminent strip mining in southern Ecuador of gold and copper ore worth US $\$ 200$ billion could and help authors to fulfil the put a serious strain on the country's legal system and its environmental policies.

Kelly Swing Tiputini Biodiversity Station, University San Francisco de Quito, Quito, Ecuador. kswing@usfq.edu.ec Luis Sempértegui Superior Court (retired), Loja Province, Ecuador.

\section{Open collaboration is key to new drugs}

As chair of the board of the Structural Genomics Consortium (SGC), I would like to acknowledge the commitment of the hundreds of scientists from industry and academia who collaborate with the SGC to make freely available synthetic probes that are potentially important to public health. You feature one such molecule, JQ1, now being investigated for blocking unwanted gene expression, in your discussion of epigenetics targets in cancer (Nature 488, 148-150; 2012).

JQ1 resulted from collaboration between SGC researchers and Jay Bradner's group at the Dana-Farber Cancer Institute in Massachusetts, building on the work of scientists at Mitsubishi Tanabe Pharma in Japan and with guidance from scientists at GlaxoSmithKline in the United Kingdom. As you point out, the huge impact of the study is due in large part to the collaborators' willingness to distribute JQ1 without restriction.

Other such examples resulting from open collaborations between industry and academia include inhibitors of the molecules JMJD3 (L. Kruidenier et al. Nature 488, 404-408; 2012), BRD4 (P. Filippakopoulos et al. Nature 468, 1067-1073; 2010) and G9-a-methyltransferase (M. Vedadi et al. Nature Chem. Biol. 7, 566-574; 2011).

Markus Gruetter University of Zurich, Switzerland. gruetter@bioc.uzh.ch 